\title{
Inovação Curricular e Tecnologia de Ensino e Aprendizagem para Inclusão Social: a experiência do Programa de Honra em Estudos Ambientais e Desenvolvimento Humano e Sustentável da Universidade Austral do Chile Curriculum Innovation and Teaching and Learning
Technology for Social Inclusion: the experience of the Honor
Program in Environmental Studies and Sustainable Human
Development of the Austral University in Chile
}

\author{
Carlos Alberto Cioce SAMPAIO* \\ Juan Carlos SKEWES ${ }^{* *}$ \\ Frederick CONWAY***
}

\begin{abstract}
RESUMO
Os Programas de Honra ( $\mathrm{PH})$ não são comuns no Chile. Uma experiência proveitosa nas universidades norte-americanas, pensada em termos da realidade educacional regional universitária e sob o prisma da transdisciplinaridade, prova ser útil como uma estratégia que une a qualidade, a inovação e a equidade na docência. Descreve-se a disciplina Filosofias do Desenvolvimento no âmbito da experiência do PH em Estudos Ambientais e Desenvolvimento da UACH, que acabou se transformando em um projeto de intervenção social numa comunidade indígena, interconectando ensino/aprendizagem e pesquisa. Além de destacar a contribuição do PH à formação de graduação e no atendimento às demandas socioambientais de comunidades com desvantagens históricas a partir da disciplina, o artigo assinala as condições que propiciam o melhoramento do ensino superior num contexto como o chileno e o brasileiro de profunda desigualdade.
\end{abstract}

Palavras-Chave: tecnologia de ensino; tecnologia de aprendizagem; inclusão social; educação superior chilena; inovação na educação universitária; programas de formação transdisciplinar.

\footnotetext{
ABSTRACT

Honors programs are rare in Latin America, and in Chile. Stimulated by experiences in the USA, a project proposal was written. Three years of experience have proven that a Chilean honors program can

* Professor dos Programas de Pós-Graduação (Doutorado) em Ciências Contábeis e Administração e (Mestrado) em Desenvolvimento Regional. Universidade Regional de Blumenau (FURB). Contato: carlos.cioce@gmail.com.

"* Professor da Universidad Austral de Chile. Contato: jskewes@uach.cl.

*** Professor da San Diego State University. Contato: conway1@mail.sdsu.edu.
} 
serve as a model for programs elsewhere in Latin America. In the following pages we aim to provide a summary of what this experience has meant, using the most recent class, Philosophies of Development, as an example. Some background about the university and the Chilean system had to be supplied, while most of the paper deals with the particular features of this program and its immediate future. The UACH program is of interest not only because of its Latin American context, but also because it is focused on a particular theme, Environmental Studies and Sustainable Human Development. After three years, the program has just completed its pilot phase, and so the time is right to describe its accomplishments and challenges.

Key-words: Honors Program; Higher Education in Chile; Educational Innovation; Transdisciplinarity.

\section{RESUMEN}

Los Programas de Honra (PH) no son comunes en Chile. Una experiencia provechosa en las universidades norteamericanas, pensada en términos de la realidad educativa regional universitaria y bajo el prisma de la transdisciplinaridad, prueba ser útil como una estrategia que une la calidad, la innovación y la equidad en la docencia. Se describe la disciplina Filosofías del Desarrollo en el ámbito de la experiencia del $\mathrm{PH}$ en Estudios Ambientales y Desarrollo de la UACH que acabó transformándose en un proyecto de intervención social en una comunidad indígena, interconectando enseñanza/aprendizaje e investigación. Además de subrayar la contribución del PH a la formación de graduación y en la atención las demandas socioambientales de comunidades con desventajas históricas a partir de la disciplina, el artículo señala las condiciones que propician el mejoramiento de la enseñanza superior en un contexto como el chileno y el brasileño de profunda desigualdad.

Palabras-claves: Tecnología de Enseñanza; Inclusión Social; Educación Superior Chilena; Innovación en la Educación Universitaria; Programas de Formación Transdisciplinar.

\section{Introdução}

A partir do ano 2002, um grupo de acadêmicos da Universidade Austral de Chile (UACH), associados ao Centro Transdisciplinar em Estudos Ambientais e Desenvolvimento Humano Sustentável (CEAM), discute a possibilidade de implementar uma proposta de formação de graduação no âmbito de estudos ambientais. A discussão se dá no âmbito de uma universidade regional que, como é habitual no contexto chileno, acolhe alunos e alunas academicamente vulneráveis, o que é expressão direta da profunda desigualdade que se verifica no sistema educacional chileno (BRUNNER et al., 2005). Além do mais, comunidades localizadas no entorno das Instituições de Ensino Superior pouco usufruem o conhecimento científico produzido por estas, isto é, ou o conhecimento universitário não chega ao mundo da vida das comunidades ou ele, então, não serve para responder as suas demandas.

O processo de ensino-aprendizagem convencional produziu efeitos nocivos na sala de aula e nos campi universitários. A apatia dos estudantes, a mediocridade implantada como norma, a ausência de uma reflexão crítica, a exacerbação monodisciplinar na transmissão do conhecimento e os modelos autoritários de ensino, associados à absoluta desvinculação com o meio regional, são sintomas de uma situação universitária que exige melhoras substanciais.

A possibilidade de contribuir com o ensino de graduação, por meio de um conteúdo transversal, como são os estudos ambientais e de desenvolvimento humano sustentável, no marco de um programa de excelência surgiu no interior do CEAM como uma proposta pedagógica para encarar os desafios propostos indicados no parágrafo anterior. A proposta encontra acolhida no Ministério de Educação do Chile, mediante seu Programa para o Melhoramento da Qualidade do Ensino Superior (MECESUP).

Diante da oportunidade, nesse momento, no âmbito do Programa desencadeiam-se estudos e práticas que tentam gerar respostas a problemas inesperados encontrados por ocasião em que se pesquisa algo diferente (MERTON et al., 2003).

A oportunidade que o MECESUP oferece se dá no campo da inovação curricular, e o grupo do CEAM propõe um modelo de excelência. Ao implantá-lo, inspira-se nos modelos norte-americanos que caracterizam a boa parte das 
universidades desse país (LONG, 1995; FUIKS; CLARK, n.d.; SCHUMAN, 1995). A proposta se relaciona com a necessidade de encontrar as respostas pedagógicas pertinentes à realidade local e que contribuam eficazmente para diminuir a desigualdade introduzida no sistema da educação superior chileno, e não diferente no caso brasileiro: qualquer estudante que ingresse em uma universidade merece a qualidade docente que o posicione em pé de igualdade profissional e acadêmica com seus pares. Enquanto isso não ocorre, a equidade segue sendo uma utopia.

O Programa de Honra de Estudos Ambientais e de Desenvolvimento Humano da UACH teve como marco a coordenação da disciplina Filosofias do Desenvolvimento, durante o segundo semestre de 2005. A disciplina acabou conjugando uma rede de esforços universitários e comunitários, valendo-se de conhecimento formal, saber tradicional e práticas oriundas de movimentos sociais na qual se incluíram demandas socioambientais da comunidade indígena Tralcao Mapu, localizada às margens da confluência dos rios Pichoy e rio Cruces, no coração do Santuário da Natureza "Carlos Anwandter", ao sul de San José de la Mariquina, XIV Região Los Ríos (Sul do Chile). Tralcao forjou suas esperanças de desenvolvimento no ecoturismo que beneficiaria 80 famílias, contudo, nem se quer iniciou devido à contaminação do estuário valdiviano por excesso de metais provindos das atividades industriais da Fábrica de Celulosa Arauco e Constituição S.A. (CELCO), na qual acabou pondo fim a uma boa parte da vida silvestre que fazia da localidade um lugar privilegiado para a observação dos hoje quase inexistentes cisnes de pescoço negro (espécie rara na região que despertava interesse). Muitos cisnes morreram lentamente de fome devido à desaparição do luchecillo (Egeria densa) ${ }^{1}$, fonte principal de sua alimentação (UACH, 2005).

Neste artigo se descrevem as características do Programa de Honra em Estudos Ambientais e de Desenvolvimento Humano Sustentável (PHMA), proporcionando um breve resumo dos resultados alcançados, além da descrição de um de seus cursos: Filosofias do Desenvolvimento, que acabou se transformando em uma tecnologia de ensino/aprendizagem para a inclusão social, neste caso, uma comunidade indígena se beneficiou do conhecimento não só gerado na Universidade, mas por ela articulado e facilitado. Este estudo apoiou-se tanto na documentação gerada pela experiência, contida em seu relatório de autoavaliação, de outubro de 2005, como nos depoimentos de docentes, estudantes e avaliadores que o Programa teve. De especial importância são os relatórios de avaliação das professoras Jessica Cassleman ${ }^{2}$ e Bernice Braid $^{3}$, os quais representam um relevante insumo para a reflexão que segue.

É importante que se diga que este estudo é parte integrante de uma trilogia que iniciou com um primeiro artigo publicado na própria Revista Desenvolvimento e Meio Ambiente (FERnANDEs; SAMPAIO, 2008), tratando sobre temas mais conceituais relacionados à problemática socioambiental e sua compreensão a partir do enfoque transdisciplinar, complexo e racional. Assim, neste segundo artigo, o mérito não é demonstrar domínio da literatura, mas a capacidade de produzir conhecimento aplicado a demandas comunitárias reais, no qual conhecimento científico complementa outras formas de saberes e práticas fora dos muros das Instituições de Ensino Superior. É fato que esse artigo baseou-se em duas versões anteriores, uma publicada em inglês junto ao Comitê de Programas de Estudos de Honra Norte-Americano (sKewes et al., 2006) e a outra publicada em castelhano em um livro que trata sobre inovações curriculares chilenas (SKEWEs et al., 2007). Antecipa-se, aqui, que já está em elaboração um terceiro artigo que completa a trilogia, no qual se descreverá e analisará uma experiência brasileira que está em curso no litoral paranaense, inspirada em parte pelo projeto demonstrativo chileno e a experiência cinquentenária norte-americana.

\section{Programa de Honra em Estudos Ambientais e de Desenvolvimento Humano Sustentável}

As motivações para criar um Programa de Honra em Estudos Ambientais e de Desenvolvimento Humano Sustentável (PHMA) foram de dois tipos: de uma parte,

\footnotetext{
${ }^{1} \mathrm{O}$ luchecillo (Egeria densa) desapareceu devido às altas concentrações de sulfato dos efluentes da indústria de celulose que fizeram diminuir o bicarbonato de cálcio necessário para que se obtenha dióxido de carbono $\left[\mathrm{CO}_{2}\right]$, que permite realizar a fotossíntese (UACH, 2005).

${ }^{2}$ Jessica Cassleman é Vice-Decana da Faculdade de Honra da Washington State University. A sua segunda visita ao programa realizou-se no mês de janeiro de 2006. A professora Cassleman acompanhou o início do desenho da experiência, a partir de junho de 2003.

${ }^{3}$ Bernice Braid é Decana da Pró-Reitoria de Recursos Acadêmicos e Educacionais da Long Island University de Nova York-Brooklin, e foi presidenta do Nacional Collegiate Honors Council (NCHC), única associação do mundo de programas de honra. A Bernice Braid se encomendou a avaliação do Programa, o que aconteceu no mês de outubro de 2005 .
} 
acadêmicas - vinculadas à inovação docente - e, de outra, temáticas - encarar a problemática ambiental desde uma perspectiva transdisciplinar. A combinação de ambas as inspirações surge como resultado de um programa bastante incomum no contexto dos programas de honra em nível internacional. Em geral, estes são abertos e tentam, tal como o PHMA, estimular o pensamento crítico, a criatividade, a preocupação pelo meio, a liderança e a flexibilidade entre seus participantes, mas não se restringem a um tema (LONG, 1995).

Quanto ao aspecto acadêmico, emoldurado nos parâmetros estratégicos da UACH, o PHMA teve como preocupação principal acolher, acompanhar e projetar a motivação de estudantes que não encontravam em seus cursos universitários respostas suficientes às suas inquietudes. Com a criação de uma comunidade acadêmica, centrada em torno da discussão de problemas e vinculada ao entorno regional, pretendeu-se satisfazer a demanda estudantil, simultaneamente com a abertura de um espaço para docentes motivados pela busca de novos estilos de ensino-aprendizagem.

Aproveitando uma rede acadêmica de indiscutível transcendência na Universidad Austral de Chile, a temática meio ambiente e desenvolvimento permitiria construir pontes entre as disciplinas, para tentar responder aos desafios que impõem uma sociedade complexa em termos de encontrar respostas integrais a seus problemas ambientais e de desenvolvimento humano.

Com a possibilidade de inovar o currículo acadêmico de formação geral (cursos facultativos), propôs-se a criação de um Programa de Honra em Estudos Ambientais e Desenvolvimento Humano Sustentável (PHMA). Em abril de 2003, começa sua difusão, contando com o apoio proporcionado pelo MECESUP. Desde então, noventa e cinco estudantes (entre aproximadamente 200 postulantes) e cinquenta e cinco professores se viram envolvidos num programa cujo desafio principal foi o de transformar a docência de ensino superior em uma experiência significativa de aprendizagem em um contexto comunitário. Foram também convidadas a participar pessoas de diferentes procedências, regional, nacional e internacional, que passavam pela $\mathrm{UACH}$.

A aposta do PHMA apontou substantivamente a forjar um espaço de criatividade no âmbito da sala de aula com uma projeção para pensar e agir no meio social e ambiental. Desde sua criação, em 2003, o programa convocou, anualmente, vinte alunos e alunas de todos os cursos da universidade ${ }^{4}$ a iniciar um caminho juntos, numa sequência de três cursos, cujo objetivo final é de forjar uma visão holística, transdisciplinar e sensível diante de temas sociais e ambientais, entre os quais assumirão papéis de liderança tanto na academia como no mundo das instituições públicas e privadas 5 .

A possibilidade de forjar uma alternativa docente foi desenvolvida a partir das disciplinas e, ao fazê-lo, socializaram-se entre os professores e professoras novas maneiras de acompanhar a formação de estudantes universitários. A fim de assegurar o cumprimento dos objetivos propostos, o PHMA propôs certos requisitos aos cursos a serem oferecidos, a saber: (a) que sejam transdisciplinares; (b) focalizados em situações mais do que em conteúdos específicos; (c) a incorporação de não menos de três professores de pelo menos dois centros de ciências diferentes em sua condução; (d) uma metodologia de aprendizagem ativa na sala de aula, incluindo a discussão de casos, a simulação de situações e o trabalho de campo como suas principais ferramentas; (e) um sistema de avaliação alternativo para substanciar os processos de ensino e aprendizagens (exibições, produções audiovisuais, folhetos); e (f) ênfase na capacidade de questionar de parte dos alunos mais do que de responder de parte dos professores.

Os cursos oferecidos pelo PHMA foram: Do Multidisciplinar ao Transdisciplinar: Saboreando o Inesperado (Segundo Semestre, 2003); Biodiversidade Marinha Costeira no Sul de Chile, seu Conhecimento e Conservação (Segundo Semestre, 2003, e Primeiro Semestre, 2004); Teoria e Solução de Problemas de Conservação Biológica (Primeiro Semestre, 2004); Mudança Global (Primeiro Semestre, 2004); História Ambiental e Cultural dos Bosques

\footnotetext{
${ }^{4}$ Produto da aprendizagem obtido nos três primeiros anos, e dado o incremento no número de postulações ao programa procedeu-se ao aumento do número de participantes para 25 para a quarta turma e acrescentou-se um curso introdutório de dez alunos.

${ }^{5}$ O Programa de Honra atualmente é dirigido pelo professor Juan Carlos Skewes, tendo como Diretor Executivo o professor Teodoro Kausel. O Conselho Assessor é constituído pelos professores Charlotte Lovengreen, do Instituto de Física; Hernán Neira, do Instituto de Filosofia e Estudos Educacionais; María Eugenia Solari, do Instituto de Ciências Sociais; Pablo Villarroel, do Instituto de Comunicação Social; Angélica Aguilar, do Instituto de Silvicultura; Selín Carrasco, do Centro de Informática, e Francisco Azinheira, da Universidade Católica de Temuco.
} 
Temperados do Sul de Chile (Segundo Semestre de 2004); Empreendimentos Associativos para o Desenvolvimento Sustentável em Comunidades Rurais (Segundo Semestre de 2004); A Água como Meio para a Aprendizagem do Ecossistema e seu Uso Sustentável (Primeiro Semestre de 2005); Bioética, Desenvolvimento Sustentável e Conservação de Áreas Naturais no Chile (Primeiro Semestre de 2005); Filosofias do Desenvolvimento: Epistemologias e Biologia do Conhecimento, Mudança Cultural e Socioeconomia (Segundo Semestre de 2005).
Um número significativo de professores e professoras, tanto da Universidade Austral de Chile como de outras instituições de educação superior e de investigação, participou desses cursos. No Gráfico 1 a seguir, aponta-se a distribuição dos docentes segundo os Departamentos de sua procedência.

Os cursos oferecidos pelo PHMA incluem saídas de campo. Na Tabela 1 que segue, mencionam-se as saídas de campo realizadas em cada disciplina:

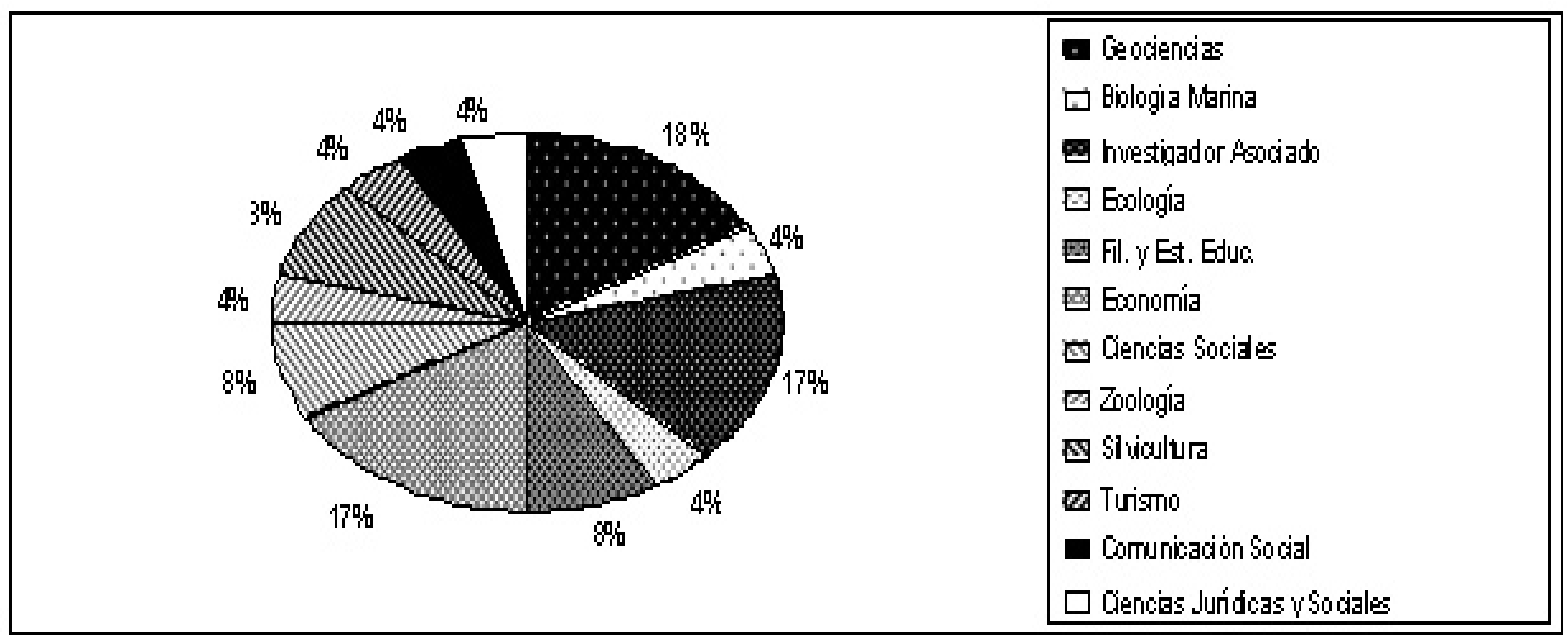

GRÁFICO 1 - DISTRIBUIÇÃO DE DOCENTES POR DEPARTAMENTOS DE PROCEDÊNCIA.

TABELA 1 - SAÍDAS A CAMPO REALIZADAS NO PHMA.

\begin{tabular}{|c|c|}
\hline Destino & Nome do Curso \\
\hline Oncol-Curiñanco & "Teoria e solução de problemas de conservação biológica". \\
\hline Panguipulli - Coñaripe - Liquiñe & $\begin{array}{l}\text { "Empreendimentos associativos para o desenvolvimento sustentável em comunidades } \\
\text { rurais" }\end{array}$ \\
\hline Región del Calafquén & $\begin{array}{l}\text { "Historia Ambiental e Cultural dos Bosques Temperados do Sul do Chile nos últimos } 10.000 \\
\text { anos". }\end{array}$ \\
\hline Ensenada-Petrohue. & "A Água como meio de aprendizagem para entender o ecossistema e seu uso sustentável”. \\
\hline Río Futa- Isla Mapu-pullu & "Bioética, Desenvolvimento Sustentável e Conservação de Áreas Naturais no Chile" \\
\hline $\begin{array}{l}\text { Planta de Tratamiento de Aguas Décimas } \\
\text { Valdivia (Guacamayo) }\end{array}$ & "A Água como meio de aprendizagem para entender o ecossistema e seu uso sustentável". \\
\hline Corral- Los Liles- Chaihuin & $\begin{array}{l}\text { "Empreendimentos associativos para o desenvolvimento sustentável em comunidades } \\
\text { rurais" }\end{array}$ \\
\hline$\underline{\text { Tralcao }}$ & $\begin{array}{l}\text { "Filosofias do Desenvolvimento: Epistemologias e biologia do conhecimento, mudanca } \\
\text { cultural e socioeconomia ". }\end{array}$ \\
\hline Yaldad (Chiloé) & "Biodiversidade Marinha Costeira no Sul do Chile, seu Conhecimento e Conservação". \\
\hline
\end{tabular}


É de especial interesse assinalar que a participação dos docentes e técnico-administrativos do PHMA é absolutamente voluntária e gratuita (não há remuneração aos docentes). Constitui exceção a secretária, cuja metade do tempo é financiada pelos gastos operacionais do projeto. Mas ela é também um importante membro da comunidade constituída no PHMA; sua interação permanente com docentes e estudantes, sua dedicação e compromisso com a tarefa, provam ser ingredientes imprescindíveis em experiências deste tipo.

A participação de estudantes no PHMA se viabilizou por meio de editais abertos, cujas inscrições foram realizadas via Intranet, no portal da universidade (www.uach.cl). As inscrições foram avaliadas pelas comissões selecionadoras integradas por docentes e estudantes do programa (claro, com exceção da primeira postulação). Os critérios empregados nas avaliações consideraram: (a) rendimento acadêmico do ou da estudante segundo o informado pela Direção de Registro Acadêmico (em geral, espera-se que se localize no quintil mais alto de sua carreira); (b) distribuição homogênea por curso/centro (espera-se em média contar com até dois estudantes por curso); (c) motivação justificada por meio de uma carta e, eventualmente, recomendações de docentes e diretores de Centro; e (d) entrevista pessoal, com a qual se tenta avaliar o interesse da candidata e do candidato e sua trajetória pessoal.
Sobre essa base se organizaram quatro turmas do PHMA, as quais constituem um universo de estudantes heterogêneo e equilibrado, conforme se observa no Gráfico 2 (relativo apenas às três primeiras turmas).

Sediado na Casa "4", o PHMA se constituiu num espaço de encontro cotidiano e informal entre estudantes e professores. A "Casa 4" é um chalé localizado na frente do rio Valdivia, e que serve de sede ao CEAM. Graças aos aportes do MECESUP/Chile, pode-se oferecer a devida estrutura às equipes docente e discente. É um espaço flexível e aberto, incluindo uma cozinha ${ }^{6}$.

Esse caminho percorrido permitiu, conforme o Programa, alcançar resultados cruciais, como a idoneidade dos estudantes na hora de avaliar a trajetória. Os estudantes constituíram um grupo com identidade própria, ativo em iniciativas e participação coletiva nas tarefas.

Em termos gerais, o PHMA recebeu uma nota 5,7 por parte de seus professores (uma amostra de sete professores) - em escala de 1 a 7; 5,9 de seus estudantes (uma amostra de dezenove); e 5,1 dos dez diretores de Centro questionados. No caso dos diretores de Centro é especialmente significativa, pois representam um juízo independente, mais crítico, para que se possa avaliar um programa em sua fase piloto.

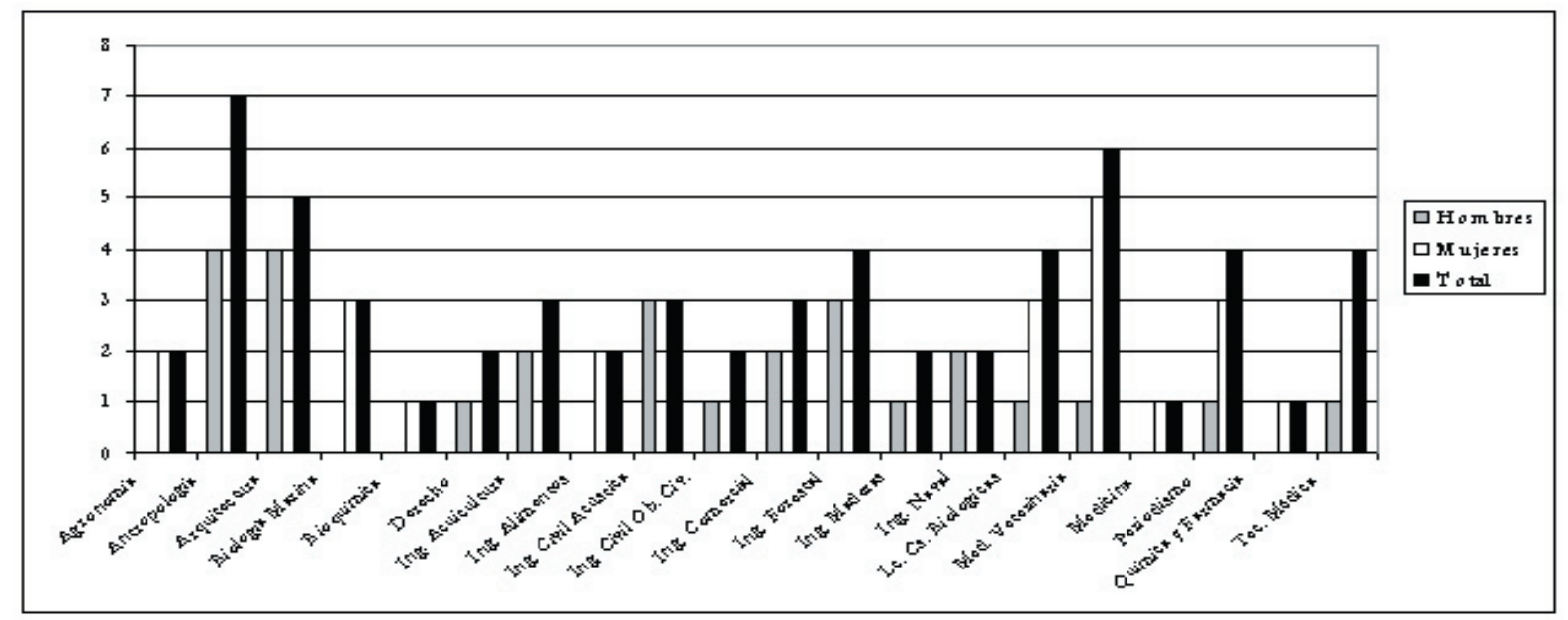

GRAFICO 2 - DISTRIBUIÇÃO DE ESTUDANTES POR SEXO E CURSO.

\footnotetext{
${ }^{6}$ Ainda que possa parecer pouco relevante, acredita-se que não o é: os e as estudantes tiveram livre acesso à Casa "4" (sem restrições de horários) e uso livre de equipamento portáteis (câmeras fotográficas, vídeos e outros) até o presente não houve prejuízos. Isso denota, em nossa opinião, o sentido de responsabilidade entre nossos estudantes.
} 
No gráfico que segue, decompõem-se algumas qualificações outorgadas ao PHMA por seus professores, estudantes e diretores de Centro.

O Gráfico 3 aponta: a) o PHMA é reconhecido de maneira similar pelos diferentes grupos ouvidos; b) não é de toda coincidência à capacidade que o Programa de Honra tem de posicionar temas no espaço universitário, questão que é altamente valorizada pelos estudantes e acadêmicos. O PHMA é reconhecido pelos diretores, porém não é apreciado pelos estudantes; c) destaca-se o PHMA como um projeto inovador não só para a UACH, mas também para outras universidades do país; e d) o ponto mais frágil é a difusão do PHMA. Salvo a percepção que os professores têm a respeito da popularidade do programa entre seus estudantes, que, em geral, se reconhece apenas como regular este aspecto.

A isso contribui: a) a curta duração do programa; b) a área temática abordada; enquanto o tema ambiental é transversal e especialmente propício para um programa deste tipo, não é menos verdadeiro que engendra visões desencontradas, preconceitos e resistência numa comunidade que se vê diante de demandas contraditórias entre as visões produtivistas, preservacionistas e conservacionistas; e c) a estrutura institucional atual também não contribui para um programa como o descrito. A $\mathrm{UACH}$, como outras universidades do país, organiza-se em torno de seus Centros e uma boa parte das decisões de política universitária está determinada pelos interesses particulares de cada um deles. Entretanto, o que ocorre quando um programa transdisciplinar não está vinculado a algum centro de ciências na universidade, o que parece ser coerente, e que pode até conseguir simpatias e o voluntarismo de seus gestores, mas dificilmente terá apoio político institucionalizado para sua implantação.

O Programa de Honra é uma oportunidade para ultrapassar as fronteiras disciplinares. Esta forma de educar representa a maneira de incorporar o pensamento transdisciplinar em quem se desenvolve no mundo acadêmico, seja como pesquisador, seja como docente, seja como estudante. A aprendizagem de uma ex-estudante do programa sugere que a transdisciplina possibilita agrupar conhecimento fragmentado, graças à visão crítica de diferentes perspectivas, surgida ora pelas causas do problema de pesquisa, ora pelo entorno afetado por este. A transdisciplina entrega, segundo este depoimento, as ferramentas adequadas para vincular diversas formas de pensar e, assim, enriquecer a capacidade de aprendizagem. Semelhante vínculo se dá no contexto de uma comunidade acadêmica: trata-se da formação de equipes de trabalho, com uma perspectiva ampla, com a unificação dos conhecimentos e a transdisciplina realizada na prática. O depoimento é eloquente em termos de se dar conta de uma nova modalidade educativa: "O primeiro semestre me perguntava de qual parte formava eu disto, mas depois me

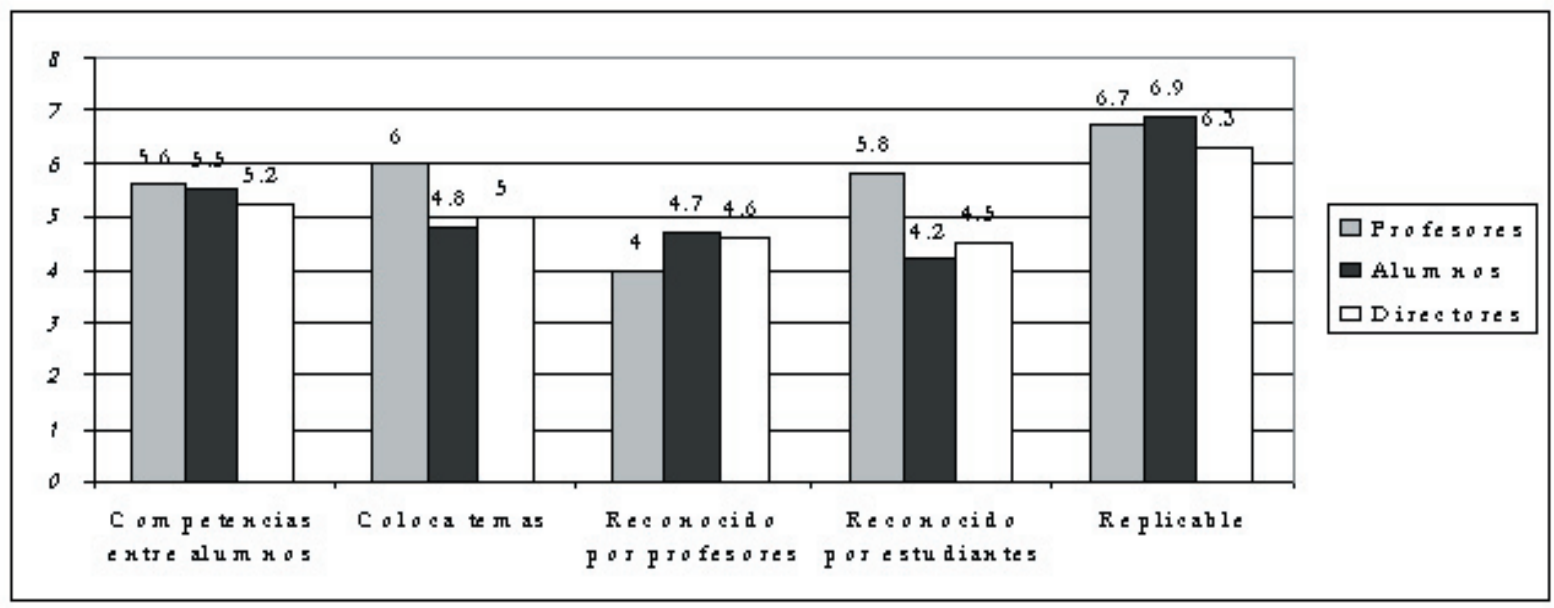

GRÁFICO 3 - COMPARAÇÃO DAS AVALIAÇÕES ENTRE PROFESSORES, ESTUDANTES E DIRETORES DE CENTRO NOS ASPECTOS CRÍTICOS DO PROGRAMA DE HONRA. 
dei conta que se me apresentavam as ferramentas, mas que ninguém eu mesmo iria buscar o caminho", afirma.

A reflexão no interior do Programa de Honra passa por muitas perspectivas. O desafio para um estudante de honra é, pois, desenvolver a lucidez necessária para dar conta das múltiplas arestas de problemas que não são apenas científicos, mas também politicamente complexos.

Uma experiência como a do Programa de Honra se verá coroada quando algum de seus ex-alunos ou alunas, como acadêmicos, chegue a ministrar uma aula e repassar uma nova visão; um novo modo de entender as coisas. Um primeiro passo nesta linha foi a criação de uma rede de exalunos, orientada para a criação e execução de projetos com perspectivas transdisciplinares em temas de meio ambiente e desenvolvimento sustentável. Sobre este ponto, há no posfácio (depois das considerações finais) uma revelação animadora.

"Como estudantes cremos que foi realmente um privilégio fazer parte deste curso já que graças à formação integral e participativa obtivemos além das noções básicas da transdisciplina, as idéias de que respeito, humildade e compromisso são fundamentais dentro das relações humanas", é a forma como uma das egressas do Programa avalia sua participação. É especialmente significativo que, entre outras coisas, os estudantes tenham pressionado a Universidade para criar um Mestrado em Ciências Ambientais. Estudantes do Programa vêm assumindo papéis diretivos em centros e em organizações estudantis, além de movimentos sociais como Ação pelos Cisnes e o recém-criado Centro para a Restauração do Santuário do Rio Cruces, deflagrado pelo dano socioambiental ocorrido no Santuário (anteriormente mencionado).

Os estudantes tiveram uma ativa participação nos principais eventos que fizeram parte do Programa de Honra, incluindo: exposição no auditório principal da Universidade Austral de Chile; um standard na IV Feira Ambiental da Região dos Lagos; a produção de uma página web sobre Biodiversidade e Fundo Marinho (http: //www.guiamarina.com/yaldad); fórum sobre os Efeitos da Fábrica de Celulose sobre o Rio Cruces (anteriormente mencionado) e as atividades desenvolvidas com professores visitantes do Programa, as que incluem uma oficina sobre resolução de conflitos ambientais com o professor Emmet Fiske da Washington State University.

O Programa estabeleceu vínculos acadêmicos com a Universidade de Montana, a Pacific Lutheran University, a Washington State University, além dos contatos iniciais com o Centro O Almendral, San Felipe, Universidad Metropolitana de Porto Rico. Acolheu ainda as visitas de Charles Bergman da Universidade Pacific Lutheran de Washington (Estados Unidos), Jessica Cassleman, Vice-decana do Programa Honors da Washington State, Frederick Conway do Departamento de Antropologia da Universidade Estatal de San Diego, Douglas Lind, Diretor do Departamento de Filosofia da Universidade de Idaho, Jill Belsky, Socióloga Ambiental da Universidade de Montana USA, Sophie Oldfield do Departamento de Médio Ambiente e Ciências Geográficas da Universidade de Cape Town, África do Sul, e de Carlos Alberto Cioce Sampaio, da Universidade Regional de Blumenau, que recentemente concluiu um estágio pós-doutoral sobre ecossocioeconomia.

Finalmente, é de destacar que um dos objetivos de maior alcance do programa, sua replicabilidade, começa a perfilar-se por meio de uma proposta para a Universidade Regional de Blumenau (Santa Catarina, Brasil). Esta iniciativa está permitindo pensar um Programa de Honra nessa universidade e criou um vínculo com os estudantes do Programa de Honor chileno, que já começaram a estagiar e interagir a partir do ano de 2006 (SAMPAIO et al., 2006). Também sobre este ponto, há no posfácio uma revelação animadora.

Tal como assinalam as avaliadoras externas, o PHMA conseguiu constituir-se em uma experiência transdisciplinar que, mediante um formato de aula tipo oficina, gerou entusiasmo e confiança entre seus participantes. Há um claro sentido, assinala Jessica Cassleman, de aprender juntos. Os estudantes encontraram um lar na Casa "4", e a experiência se tornou vinculada à comunidade. $\mathrm{O}$ espaço se deu para uma genuína inovação pedagógica. O que cabe agora é que o programa de honra se desloque para a universidade inteira.

\section{Filosofias do Desenvolvimento: um ensino alternativo}

A disciplina Filosofias do Desenvolvimento constituiu um exemplo de inovação de tecnologia de ensino-aprendizagem para a inclusão social, no sentido que possibilitou que demandas comunitárias identificadas fossem atendidas no âmbito do PHMA. A proposta desta 
disciplina (ou, melhor, interdisciplina) conectou o ensino e a pesquisa aplicada. Também não deixou de ser uma atividade de extensão dado que os trabalhos dos estudantes serviram de projetos demonstrativos para a comunidade incubada, Tralcao Mapu. Além das desvantagens históricas que já possui como comunidade indígena, Tralcao ainda sofre os impactos de um dano socioambiental que dificultou o acesso e o uso da biodiversidade de seu território, conforme apontado anteriormente.

Efetivamente, pesquisaram-se alternativas de desenvolvimento realizadas em outras localidades chilenas e suscetíveis de replicar-se em Tralcao, mais especificamente no contexto do Projeto intitulado "Fortalecimento da Identidade Cultural, Melhoramento da Gestão Ecoturística e Habilitação em Inovação Tecnológica para uso Sustentável dos Recursos Naturais no Borde Costeiro para a Comunidade Indígena Tralcao Mapu (Localidade de Tralcao, Municipalidade de San José da Mariquina, Região Los Riós)", vinculado ao Programa Ecorregião dos Lagos Sustentável, que estava implantando a Agenda 21 Local no Município. Além do apoio do Centro de Estudos Ambientais (CEAM) e do Programa de Honra, outros órgãos da Universidade Austral do Chile o apoiaram: Instituto de Turismo, por intermédio do seu diretor, Edgardo Guillermo Oyarzún Mendez, e de uma aluna do curso de especialização de turismo rural, María Carolina Cárcamo Galaz, e o Instituto de Antropologia, por meio de um projeto de monografia de licenciatura de um aluno, coordenado por Pedro Mauricio Ivan Huenulef Oporto (skewes et al., 2005).

Os objetivos específicos para o trabalho dos estudantes foram: a) identificar experiências chilenas que se qualificavam na direção da ecossocioeconomia, isto é, que conservam modos de vida tradicionais e preservam a biodiversidade; geração de trabalho e renda sob a perspectiva de modos de produção mais associados; revigoramento dos significados de virtude humana e do próprio Estado, distanciados da lógica: privatizam-se lucros de curto prazo e socializam-se prejuízos sociais e ambientais de médio e longo prazo; e utilização apropriada dos chamados recursos naturais e das capacidades humanas locais; e b) produzir trabalhos que possam servir de proposta de implantação de práticas ecossocioeconômicas no âmbito do Projeto da Comunidade Indígena Tralcao Mapu. Para isso, os estudantes dispuseram de materiais bibliográficos pertinentes, além de outros antecedentes requeridos para sua pesquisa, disponibilizados no ambiente de aprendizagem virtual, SIVEDUC, da UACH (SAMPAIO et al., 2005).

Por conseguinte, os e as estudantes do curso tiveram como tarefa pesquisar projetos de desenvolvimento territorial sustentável demonstrativos e, ao final do curso, apresentar os resultados de suas pesquisas à comunidade de Tralcao, à qual cabia pronunciar-se a respeito da pertinência, clareza e replicabilidade da proposta sugerida por cada grupo de estudante.

Em seu aspecto teórico, a proposta sugeriu três módulos teórico-empíricos: a) Epistemologias do Conhecimento: discutiram-se as formas de conhecimento, formalizado ou popular, a intuição e a percepção e suas relações com o conhecimento cognitivo; democratização dos processos de desenvolvimento; níveis de conhecimento e mudança cultural; se analisam as contradições entre a universidade dos países chamados em desenvolvimento e as comunidades locais; b) Biologia do Conhecimento e Mudança Cultural: discutiram-se as teorias da evolução biológica e o surgimento da cultura como mecanismo de evolução; os filtros sensoriais, o sistema nervoso e a capacidade de realizar; criatividade e inovação; e c) Ecossocioeconomia: um desenvolvimento a escala humana, relevando indicadores de sustentabilidade, mais do que o IDH, a Pegada Ecológica. Discutiram-se as escolas econômicas e as experiências de gestão organizacional e interorganizacional que promovem o desenvolvimento territorial sustentável e que podem ser chamadas de Ecossocioeconomia das Organizações, tais como: arranjo socioprodutivo de base comunitária (APL.Com); turismo comunitário e solidário; fórum de agenda 21 ; orçamento participativo; economia solidária ou descalça (dentre elas, o comércio justo e a economia de comunhão); responsabilidade social empresarial.

Partiu-se de duas hipóteses prévias que conectam esses módulos apresentados anteriormente: (1) que a ecossocioeconomia se baseia em uma nova ação social orientada não só por uma racionalidade utilitarista, mas também por uma racionalidade mais valorativa, baseada no saber, na prática e no conhecimento local, que, muitas vezes, é ironicamente qualificada como subjetiva, como se não tivesse nela elementos constitutivos de cognição; e (2) que a subjetividade (experiência humana), distante do individualismo exacerbado, pode constituir-se em um elemento enriquecedor nos processos de tomada de decisão, como mostram estudos em neuropsicologia e 
biologia do conhecimento (TUAN, 1980; BERKES, 1996; LÉVISTRAUSS, 1997; OYARZÚN, 1998; VARELA, 2003; MATURANA; VARELA, 2001). Como sugerem Max-Neef (2005), negar o subjetivo é negar as diferenças, ou seja, a experiência de individualidade do ser humano.

O eixo empírico se centrou sobre o tema da ecossocioeconomia. A ecossocioeconomia está imbricada na discussão sobre o desenvolvimento territorial sustentável (uma derivação do ecodesenvolvimento). Pode-se dizer que, enquanto o ecodesenvolvimento privilegia o enfoque epistemológico-teórico, a ecossocioeconomia privilegia o enfoque metodológico-empírico. Ela se dá no mundo da vida, nas comunidades, nas organizações, nos domicílios, onde os problemas e suas soluções acontecem, e raramente são devidamente qualificados. É uma teoria pensada a partir das experimentações, das complexidades do cotidiano - inspiradas no que Sachs (2004) chama de enciclopédia do cotidiano -, das contradições inerentes à mudança paradigmática que se deseja quando se pensa nas limitações do utilitarismo economicista e que, muitas vezes, não se dá na velocidade que se deseja. A ecossocioeconomia privilegia as experimentações que possibilitam pensar uma nova economia, que na literatura de enfoque heterodoxo é denominada também por economia social, socioeconomia, socioeconomia solidária, economia descalça, economia popular solidária e economia solidária. Resguardadas as singularidades destas denominações, todas privilegiam problemas microeconômicos com soluções de base territorial, nos quais perpassam pela perspectiva da endogenia e do empoderamento das comunidades locais (SAMPAIO, no prelo).

Mais precisamente, a ecossocioeconomia das organizações privilegia os estudos que possibilitam a viabilidade macro (interorganizacional) e microeconômica (organizacional) de grupos organizados ou quase organizados articulados, chamados de arranjos socioprodutivos de base comunitária (emprendimentos comportilhados), e que ainda predominam certa inovação de práticas reconhecidas sob o eixo extraorganizacional (do entorno ao organizacional), em que se valoriza o conhecimento tradicional-popular, com seus saberes e práticas, caracterizado pela capacidade de gerar demandas e propostas que não se distanciam nem se desvinculam das peculiaridades do cotidiano, a partir da mirada das próprias pessoas (SAMPAIO, 1996; no prelo).

O que conecta todos esses módulos teórico-empíricos é a busca de elementos práticos que ajudam a solucionar o problema de pesquisa, isto é, melhorar as condições de bem-estar de comunidades tradicionais, com desvantagens históricas, pelo uso sustentável da biodiversidade.

Teve-se como objetivo principal refletir criticamente a respeito do modelo de desenvolvimento e explorar alternativas baseadas num novo modelo, chamado ecossocioeconomia, caracterizado pela cooperação, a solidariedade, a articulação de experiências e numa nova cultura que valoriza o conhecimento popular (com seus saberes e práticas) tanto quanto o acadêmico, o conhecimento prático tanto quanto o teórico, as soluções próprias tanto quanto as externas, que impulsiona a inovação e a criatividade, que procura reconhecer o que nos dá identidade num contexto global, que propõe uma nova universidade mais próxima da comunidade, capaz de falar uma linguagem compreensível às comunidades.

As aulas foram espaços de encontro entre expertos, colaboradores e convidados não-acadêmicos (chamados doutores descalços), de maneira que o conhecimento científico fosse complementado por outras formas de saberes e práticas. As aulas se iniciavam a partir dos professores coordenadores do curso (neste caso três: um antropólogo, um engenheiro florestal e um administrador), que apresentavam os convidados acadêmicos e nãoacadêmicos do dia, inclusive, quando se fez necessário, contando com lideranças da comunidade indígena.

Cada aula tinha um professor responsável (entre os três coordenadores) eleito previamente, que a conduzia, limitando-se para cada exposição (geralmente eram duas conferências) cerca de vinte minutos, deixando previamente um documento de base de cada palestra para sua leitura. Ao todo, ao longo da (inter)disciplina participaram oito professores, além dos três professores responsáveis, e quatorze convidados não-acadêmicos. Sugeriu-se que o professor responsável estimulasse metodologias participativas. Os convidados, tal como os estudantes, faziam comentários depois da conferência ou então participavam por meio de formulação de perguntas. Cada aula contou com elementos audiovisuais orientados a sensibilizar, como um relato histórico, um poema, um depoimento de alguém, uma imagem ou objeto. Toda aula era produzida uma ata, realizada por dois alunos, cuja função era de recontar os elementos fundamentais que foram tratados para que os estudantes ausentes pudessem acompanhar. 
Um aluno do curso de graduação em antropologia, que estava realizando seu trabalho de conclusão de curso em Tralcao, tinha a função permanente de articular as demandas comunitárias com as ofertas propostas pelos estudantes do Programa de Honra. Coordenava junto aos líderes da comunidade as saídas a campo que se fizeram necessárias. Os alunos e alunas foram divididos em equipes para descrever e sistematizar os projetos demonstrativos comunitários considerados exitosos e que puderam ser compreendidos como exemplos de acordos socioprodutivos de base comunitária. Entre tais experiências se encontravam: turismo comunitário em unidades de conservação, plataforma de comércio justo, microcrédito popular e feiras populares. Todas elas eram discutidas a partir dos conteúdos vistos em sala de aula e aplicados às demandas de Tralcao.

Utilizando-se um formulário qualitativo de coleta de dados, cada equipe produziu uma proposta efetiva, respeitando os critérios apontados na Tabela 2, para que pudesse ser replicada no âmbito da comunidade indígena.

A atividade de encerramento deste curso (ou exame final) consistiu na apresentação dos projetos realizados pelos estudantes ante os olhos críticos da comunidade. As apresentações incluíram uma exibição em PowerPoint ou poster ou uma exposição oral.

Obtiveram-se as qualificações que se indicam na Tabela 3 para os projetos apresentados de acordo aos critérios da comunidade e dos professores:

É interessante sublinhar que as avaliações foram bastantes críticas e que, em um caso, levaram dois estudantes a reprovarem, o que não tinha ocorrido ainda no Programa. O fato é interessante já que refletiu o pouco compromisso por quem deveria contribuir com aqueles que poderiam ser ajudados. Do mesmo modo, fez-se notar que professores e membros da comunidade valorizaram as propostas de maneira diferente, privilegiando, no primeiro caso, os

TABELA 2 - PAUTA DE AVALIAÇÃO DE TRABALHOS DE ESTUDANTES.

\begin{tabular}{|l|l|l|}
\hline $\mathbf{N}^{\mathbf{0}}$ & Critérios de Avaliação & Nota \\
\hline 1 & Apresentação do grupo foi com linguagem escrita e oral compreensíveis. & \\
\hline 2 & $\begin{array}{l}\text { O Grupo deixou claro que a experiência observada trouxe conhecimentos para a } \\
\text { Comunidade de Tralcao. }\end{array}$ & \\
\hline 3 & $\begin{array}{l}\text { O Grupo deixou claras as oportunidades e potencialidades da experiência observada que } \\
\text { poderiam ser utilizadas pela Comunidade de Tralcao. }\end{array}$ & \\
\hline 4 & $\begin{array}{l}\text { O Grupo apresentou ações que poderiam ser imediatamente realizadas pela Comunidade de } \\
\text { Tralcao a partir da experiência observada. }\end{array}$ & \\
\hline
\end{tabular}

TABELA 3 - QUALIFICAÇÕES RECEBIDAS PELOS TRABALHOS APRESENTADOS ANTE A COMUNIDADE.

\begin{tabular}{|c|c|c|c|}
\hline \multirow{2}{*}{ Título del Proyecto } & \multicolumn{3}{|c|}{ Qualificação (De 1 até 7) } \\
\hline & Comunidade & Professores & Média \\
\hline $\begin{array}{l}\text { Rede Licanhuasi de Turismo da Reserva Nacional Os Flamengos (San Pedro Atacama, } \\
\text { Região II Antofogasta, Chile) }\end{array}$ & 5,8 & 5,1 & 5,45 \\
\hline $\begin{array}{l}\text { Parque Comunitario Mapu Lahual de Maicolpi (San Juan de la Costa, Região X Los } \\
\text { Lagos, Chile) }\end{array}$ & 4,1 & 5,2 & 4,65 \\
\hline Turismo Comunitário Punucapa (Valdivia, Região X Los Lagos, Chile) & 4,9 & 6,4 & 5,65 \\
\hline $\begin{array}{l}\text { Plataforma Komyuniti Comércio Justo (Santiago, Região Metropolitana de Santiago, } \\
\text { Chile) }\end{array}$ & 2,7 & 3,1 & 2,9 \\
\hline Banco dos Pobres: Fundação de Gestão Social (Valdivia, Região X Los Lagos, Chile) & 3,9 & 5,0 & 4,45 \\
\hline $\begin{array}{l}\text { Florestal Río Cruces: Responsabilidade Social Empresarial (Lanco, Região X Los Lagos, } \\
\text { Chile) }\end{array}$ & 2,3 & 1,5 & 1,9 \\
\hline $\begin{array}{l}\text { Feira Livre de Valdivia de Domingo: Población Menzel (Valdivia, Região X Los Lagos, } \\
\text { Chile) }\end{array}$ & 5,5 & 4,1 & 4,8 \\
\hline Feira Fluvial (Valdivia, Região X Los Lagos, Chile) & 4,5 & 3,5 & 4 \\
\hline
\end{tabular}


aspectos técnico-conceituais e, no segundo, a afinidade temática proposta em relação às próprias necessidades da comunidade.

Em suma, o curso Filosofias do Desenvolvimento representou uma experiência de aprendizagem ativa, isto é, de inovação de ensino/aprendizagem para a inclusão social de uma comunidade indígena, e pôs-se a prova a capacidade dos estudantes para traduzir o conhecimento técnico em modos simplificados de socialização. Como resultado, concomitante, incubaram-se demandas comunitárias e se reafirmou o vínculo entre a universidade e seu entorno.

\section{A formação de honra para as universidades regionais}

Os pressupostos de fundo de um Programa de Honra podem formular-se em termos de perguntas: a) por que as coisas estão como estão e por que chegaram a estar desta maneira? b) poderiam as coisas estar de outro modo e qual seria essa outra maneira de estarem diferentes as coisas? c) o que sabem os que habitualmente pensam que não sabem?

$\mathrm{O}$ avançar neste marco de reflexão permitiu aos alunos e alunas do programa encontrarem avenidas próprias para circular tanto dentro da academia como fora dela. Como expressou uma aluna: "O programa foi um laboratório para mim e que me ensinou a olhar a realidade de outra maneira".

O Programa de Honra e a disciplina Filosofias do Desenvolvimento demonstraram ser uma tecnologia de ensino e aprendizagem para incluir socialmente tanto o aluno na comunidade quanto a comunidade na universidade, isto é, uma alternativa viável para a formação de excelência no contexto de universidades regionais. Sua implementação, não obstante, demanda um esforço importante em termos de vontade institucional para criar condições que favoreçam a implementação de semelhante iniciativa.

As dificuldades encontradas não são poucas, mas também não são insuperáveis. A estrutura institucional, o hábito docente e a falta de atitude ante a tarefa voluntária são três delas. Não foi fácil institucionalizar o PHMA. Aprovar seu regulamento e difundi-lo entre os diretores de Centro, gerar um tempo de dedicação docente ao Programa e possuir um orçamento estável são temas que ainda não estão definidos. O voluntariado dos docentes e gestores contribuiu com a mística necessária para fundar esta experiência, mas é suficiente para sua sustentação?
$\mathrm{O}$ fato de os docentes e estudantes estarem habituados a uma estrutura normativa tende a ser lesivo para iniciativas como estas. Fica claro que é possível aos professores e às professoras se unirem voluntariamente à experiência, da mesma forma que aos alunos e às alunas. Há o que avançar, como, por exemplo, os estudantes ainda não se dedicam aos exames e às provas. No entanto, quanto ao processo de avaliação, há o que aprender com a experiência da (inter)disciplina Filosofias do Desenvolvimento. Os hábitos de leitura são também débeis. O PHMA requer definir com maior nitidez suas exigências e compartilhá-las com seus estudantes.

Não constitui uma tarefa fácil correlacionar um modelo transdisciplinar (modelo proposto) com outro que não o é (modelo vigente), e, como o assinala uma estudante, ambos contrapõem-se completamente dentro da universidade. Como sugere uma de nossas alunas, "um tenta ampliar o modo de conhecer e pôr em prática o aprendido, e outro, baseado numa estrutura rígida, impede desenvolver discussões com professores e estudantes de diferentes áreas frente a um problema comum". Ao mesclar esses dois tipos de estruturas cognitivas, gera-se um problema: os alunos enfrentam, por um lado, um grande ônus acadêmico e, por outro, precisam compatibilizar os tempos para assumir estas duas formas diferentes de fazer educação.

Tal como o sugere Bernice Braid (2006) em seu relatório, o PHMA é incomum em sua forma. Estimula a aprendizagem ativa (produção pedagógica), vincula o campus com a região, com a comunidade (preocupação sociopolítica) e desenvolve a curiosidade intelectual entre seus estudantes, sua capacidade para trabalhar em grupos, interagir com os acadêmicos e para fortalecer neles a preocupação pela descoberta (preocupação filosófica). Coincidem as avaliadoras em ressaltar a produtividade do PHMA pela sua curta existência.

O PHMA está desempenhando um papel de protagonista no ambiente universitário. Por um lado, proporciona um selo distintivo à UACH. Mas, por outro, e de forma muito significativa, se constitui em uma encruzilhada onde se encontram a inovação pedagógica, as demandas estudantis pauperizadas no acadêmico e as comunitárias caracterizadas pelas desvantagens históricas, a vinculação com programas de graduação e pós-graduação e a necessária projeção da universidade no âmbito regional.

Indubitavelmente que semelhante papel depende em boa medida do projeto universitário em que se insere 
o PHMA e de sua institucionalização. O que se avançou até agora inclui: vinculação institucional do PHMA à Pró-Reitoria Acadêmica, reconhecimento dos créditos e atribuições orçamentárias aos cursos pela universidade, inclusão no portal da UACH e difusão por essa via, utilização da intranet para fins de inscrição ao Programa e atribuição de recursos adicionais para sua gestão. No entanto, fica ainda um caminho por percorrer neste processo. Não obstante o regulamento do PHMA (que inclui a definição de uma pequena estrutura), sua definição ou inclusão, como um centro de ciências dentro da UACH, seguem sendo um desafio.

O PHMA estando amplamente institucionalizado pode servir adequadamente aos seguintes propósitos: a) servir de laboratório para a experimentação em inovação pedagógica; o PHMA oferece uma oportunidade única de ser um laboratório docente; b) promover a missão da UACH também a partir de seus estudantes; c) inserir estudantes de ensino médio, além dos alunos de graduação, como também alunos de pós-graduação; d) vincular a atividade docente à realidade local (ao mundo da vida), tornando partícipes da vida universitária outros atores, como os próprios técnicoadministrativos e até líderes comunitários, profissionais e empresários.

Também cabe ao PHMA acolher, num primeiro ano, estudantes que, apesar de suas deficiências acadêmicas, possam chegar a entusiasmar-se com os objetivos do programa. Tal como sugere Braid (2006), sem uma oportunidade como esta, torna-se vazia a promessa de equidade.

\section{Considerações finais}

Os programas de honra devem estar vinculados aos contextos e às realidades locais. Não há receitas sobre como fazê-lo para melhor servir a seus propósitos. Cada programa de honra é diferente e está imbuído a desenvolver suas próprias virtudes e talentos. Assim, uma universidade regional chilena não pode ignorar a pauperização acadêmica de seus estudantes e a crescente e profunda divisão que o Chile experimenta em relação a sua educação superior e, consequentemente, as desigualdades socioeconômicas encontradas em comunidades como Tralcao Mapu. Excelência para um programa de honra, neste contexto, significa, em nossa opinião, gerar as estratégias adequadas para encarar a difícil tarefa de incrementar a qualidade da docência para estudantes de graduação e que o conhecimento formal se reverta em benesses para aqueles que não conseguem acesso ao sistema educacional.

Observam-se entre alunos e alunas motivação e comprometimento, não somente com o Programa, mas, sobretudo, com a comunidade incubada, conciliando a busca por conhecimento e prática social, mediante o intercâmbio de informações entre os estudantes, questionando os professores, fazendo pesquisa bibliográfica e empírica exploratória, aproximando-se de saberes e práticas locais, enfim, dos problemas comunitários, bem como de suas possíveis soluções. Enfim, a avaliação formal pode ser substituída por um processo de construção de conhecimento entre aluno, professor e comunidade.

O PHMA está imbuído a cumprir uma liderança dentro da $\mathrm{UACH}$, no sentido de propor estratégias inovadoras na docência que dêem conta da profunda desigualdade que os estudantes enfrentam ao fazer parte da educação superior. Isso é possível e viável, caso se assuma como desejável a formação de uma comunidade acadêmica constituída em torno da paixão compartilhada entre acadêmicos, estudantes e outras pessoas pela descoberta e a busca de resposta diante de circunstâncias especialmente imperativas.

Para a UACH o tema foi o meio ambiente, e era natural que assim o fosse para uma universidade que é forte em temas de silvicultura, economia ecológica, botânica, zoologia, geociência, ecologia e antropologia, entre outras disciplinas. Assim, o tema é familiar, além de seu caráter transdisciplinar. Outras universidades podem experimentar temas mais abertos, como o modelo norte-americano, ou de orientação a outras temáticas, por exemplo, educação para a paz. O importante é abrir um horizonte do pensamento universitário às possibilidades que melhor sirvam aos propósitos de um país que obstinadamente conserva e reproduz a desigualdade entre seus cidadãos.

\section{Posfácio}

Apresentam-se alguns desdobramentos atuais da disciplina Filosofias do Desenvolvimento do PHMA, na ocasião em que surge um grupo de ex-estudantes do PHMA coordenando uma das experiências mais emblemáticas no sul do Chile, que são as feiras de trocas solidárias (http: //www.truekevaldivia.cl), inclusive, atuando também no 
sul do Brasil em parceria com tutores do Programa de Honra brasileiro. Na Universidade Regional de Blumenau, com apoio da Universidade Federal do Paraná, Setor Litoral, inicia-se um Programa de Honra de Estudos em Ecossocioeconomia com filhas e filhos de famílias oriundas de populações tradicionais (agricultores familiares com forte presença de pluriatividade), jovens entre 12 a 18 anos que frequentam o ensino fundamental e médio, oriundos da Microbacia do Rio Sagrado, zona rural do município de Morretes (litoral paranaense), no qual estudantes de graduação e pós-graduação são tutores do programa. Tal estória, que por enquanto não virou história, ainda está para ser contada. Espera-se, assim, fechar a trilogia.

\section{Referências}

BERKES, F. Social systems ecological systems and property rights. In: HANNA, S. Right to nature: ecological, economics, cultural and political principles of institutions. Washington, DC: Island Press, 1996.

BRAID, B. Revisión del programa de honor en estudios ambientales y de desarrollo humano sostenible. Valdivia, 2006. mimeo

BRUNNER, J. J.; ELACQUA, G.; TILLET, A.; BONNEFOY, J.; GONZÁLEZ, S.; PACHECO, P.; SALAZAR, F. Guiar el mercado: informe sobre la educación superior en Chile. Santiago de Chile: Universidad Adolfo Ibáñez, 2005.

FERNANDES, V.; SAMPAIO, C. A. C. Problemática ambiental ou problemática socioambiental? A natureza da relação sociedade meio ambiente. Revista Desenvolvimento e Meio Ambiente, v. 18, p. 87-94, 2008.

FUIKS, C. L.; CLARK, L. Teaching and learning in Honors. Publication of the National Collegiate Honors Council, n.d.

LÉVI-STRAUSS, C. Tristes trópicos. Barcelona: Paidós, 1997.

LONG, A. A handbook for Honors Administrators: monographs in Honors Education: The National Collegiate Honors Council, 1995.

MATURANA, H.; VARELA, F. A árvore do conhecimento: as bases biológicas da compreensão humana. São Paulo: Athena, 2001.

MAX-NEEF, M. Foundations of transdisciplinarity. Ecological Econonomics, v. 5, p. 5-16, 2005.

MERTON, R. K.; BARBER, E.; SCHULMAN, J. L. The travels and adventures of serendipity: A study in sociological semantics and the sociology of science. New Jersey: Princeton University Press, 2003.
OYARZÚN, F. La persona normal y anormal y la antropología de la convivencia. Valdivia: Imprenta Universitária, 1998.

SACHS, I. Desenvolvimento includente, sustentável sustentado. Rio de Janeiro: Garamond, 2004.

SAMPAIO, C. A. C. Arranjos institucionais para o desenvolvimento sustentável local. Revista de Administração Municipal, v. 43, p. 71-82, 1996

Gestão que privilegia uma outra economia: ecossocioeconomia das organizações. Blumenau: EDIFURB, no prelo.

; FELSKI, H.; RUSCH, F. Transdisciplinaridade: a implantação do programa de honra em estudos em meio ambiente e desenvolvimento na Universidade Regional de Blumenau (FURB). In: CONGRESSO OIUDSMA: ORGANIZAÇÃO IINTERNACIONAL DE UNIVERSIDADES PARA O DESENVOLVIMENTO SUSTENTÁVEL E MEIO AMBIENTE, VI. Curitiba (PR): UFPR, 2006. Anais, 2006.

; OTERO, L.; SKEWES, J. C. Programa de asignatura filosofia del desarrollo. Valdivia: $\mathrm{UACH}, 2005$. mimeo

SCHUMAN, S. Beginning in Honors: a handbook: The National Collegiate Honors Council, 1995.

SKEWES, J. C.; SAMPAIO, C. A. C.; CONWAY, F. Honors in Chile: New engagements in the higher education system. Journal of The National Collegiate Honors Council (HIP), v. 2, p. 15-26, 2006.

Una propuesta de excelencia, inovación y equidad: el programa de honor en estudios ambientales y desarrollo humano sostenible de la Universidad Austral de Chile In: Innovación curricular en educación superior: una estrategia de desarrollo hacia el bicentenario. Valparaíso: Universidad de Valparaíso, p. 216-231, 2007. 
; SAMPAIO, C. A. C.; EGAÑA, S. La transdisciplina hecha práctica: el programa honor de estudios ambientales y desarrollo humano sostenible de la Universidad Austral de Chile. In: ENCUENTRO INTERNACIONAL: REFORMA DEL PENSAMIENTO:POSIBILIDADESY POTENCIALIDADES DE LAS UNIVERSIDADES REGIONALES. Osorno, 2005. Anales. Osorno: ULagos, 2005.

TUAN, Y. F. Topofilia: um estudo da percepção, atitudes e valores do meio ambiente. São Paulo, 1980.
UACH, UNIVERSIDAD AUSTRAL DE CHILE. Primer informe de avance: estudio sobre el origen de mortalidad y disminución poblacional de aves acuáticas en el santuario de la naturaleza Carlos Anwardter, en la provincia de Valdivia. Convenio Complementario Especifico n. 1210-1203/200411-14, 15.diciembre.2004, Dirección Regional CONAMA X Región de Los Lagos. Valdivia: UACH, 2005.

VARELA, F. J. La habilidad ética. Barcelona: Debate, 2003.

Recebido em 14 de março de 2009.

Aceito em 9 de julho de 2009. Publicado em dezembro de 2009. 